\title{
Comparison Of Initial Alignment Between Self Ligation and Conventional Ligation Systems For Decrowding Of Mandibular Anterior Teeth
}

Research Article

Nilesh Suresh ${ }^{1}$, Naveen Kumar $\mathrm{M}^{2 *}$

${ }^{1}$ Saveetha Dental College and Hospitals, Saveetha Institute of Medical and Technical Sciences, Saveetha University, Chennai, India.

${ }^{2}$ Senior Lecturer, Saveetha Dental College and Hospitals, Saveetha Institute of Medical and Technical Sciences, Saveetha University, Chennai, 600077, India.

Abstract

Self ligation orthodontics is becoming more popular recently because of the ease of ligation. The study aims to assess the efficiency of self ligating brackets compared to the conventional brackets during the initial alignment stage. Study models of 20 patients who had undergone orthodontic treatment with Damon self ligating system and conventional ligating system were included in the study. The study models were assessed for anterior arch alignment, extraction space closure and changes in intercanine widths at pre-operative stage and after 20 weeks of treatment T0, T1 ( 10 weeks), T2 ( 20 weeks). All the data about the above parameters was collected , tabulated and subjected to statistical analysis. Two-sample t-test for assessing the difference between pre- and posttreatment values among the groups were performed. A chi-square test was done to find the association between the gender and the type of ligation. There was no significant difference in the rate of alignment between the two groups at the end of 20 weeks (mandibular arch, $\mathrm{P}=0.62$ \& maxillary arch, $\mathrm{P}=0.78$ ). No significant difference in the extraction space closure (mandibular arch, $\mathrm{T} 0-\mathrm{T} 2$. $\mathrm{P}=0.76$, maxillary arch $\mathrm{T} 0-\mathrm{T} 2, \mathrm{P}=0.39$ ). Mandibular intercanine width increased from $\mathrm{T} 0-\mathrm{T} 2,1.83$ and $2.69 \mathrm{~mm}$ in $\mathrm{SL}$ and $\mathrm{CL}$ groups respectively. Chi-square association between gender and types of bracket used was found not to be statistically significant $(p>0.05)$. The SL brackets were not very effective compared to CL brackets in anterior alignment or extraction space closure during the first 20 weeks of treatment. We can conclude that the type of ligation alone does not influence the efficiency of treatment.

Keywords: Conventional Ligating; Initial Alignment; Self Ligating; Space Closure.

\section{Introduction}

Orthodontics has been continually evolving since its time of inception. There have been innumerable modifications in the bracket design as well. The quest to improve the treatment efficiency has culminated in many modern edgewise appliances. Recently, the promotion of self-ligating (SL) brackets has stimulated much controversy. Advocates claim that low-friction SL brackets along with light forces enhance the rate of tooth movement and reduces treatment time. Other advantages include decreased appointment times, improved oral hygiene, increased patient acceptance, and superior treatment results $[1,2]$.

Most claims of SL brackets have been extrapolated from in-vitro studies. A recent systematic review highlighted the limitations of in-vitro studies [3]. In particular, studies that demonstrate reduced friction in SL brackets compared with conventionally ligated (CL) brackets have been coupled with small-diameter wires in wellaligned arches with no tip and torque [4-8]. In-vitro studies are limited because they cannot comprehensively simulate a clinical scenario. Many variables can influence the quantity of friction generated during a fixed appliance system. These include archwire and bracket composition [7-9], bracket slot dimension and design, archwire dimension [10], bracket slot dimension and design, deflection of the archwire $[10,11]$, interbracket distance, deflection of the archwire $[10,11]$, and biologic factors like saliva and perturbations [12]. Therefore, it is doubtful whether the use of SL brackets has clinical benefits such as decreased resistance to sliding, faster tooth movement, and increased treatment efficiency.

Several in-vivo studies have compared the efficiency of SL and CL brackets during various stages of treatment with conflicting re-

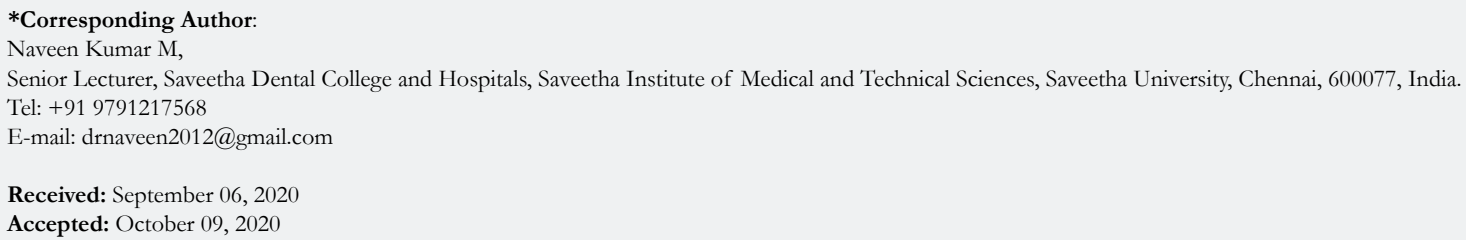

Copyright: Naveen Kumar $\mathbf{M}^{\circ} 2020$. This is an open-access article distributed under the terms of the Creative Commons Attribution License, which permits unrestricted use, distribution and reproduction in any medium, provided the original author and source are credited. 
sults. These studies analysed treatment efficiency in terms of total treatment time, number of appointments, and tooth movement during initial alignment and active space closure. Early retrospective studies reported up to 6 months' reduction in total treatment time and fewer appointments with SL brackets $[2,13]$. Other welldesigned retrospective and prospective studies reported no significant differences during initial alignment or active space closure with various SL and CL brackets [14-17].

Miles et al., [14, 16, 17] and Miles [17] postulated that SL brackets might provide a measurable benefit in extraction patients. Additionally, Scott et al., [18] suggested that SL brackets might encourage passive space closure during initial alignment. There is a relative lack of evidence that compares the efficiency of SL and CL brackets in extraction patients because most studies have investigated mixed samples. Only 2 clinical trials have compared SL and CL brackets solely in extraction patients $[15,17,18]$. This could reduce the overall treatment time. Furthermore, this might minimize the detrimental effects of active force application such as root resorption.

This study was aimed to evaluate the alignment efficiency of Self Ligation and Conventional Ligation brackets.

\section{Materials and Methodology}

The data for this study was retrieved from patient records reported from Saveetha Dental College, Chennai. Study models of 9 patients who were treated with Self Ligating brackets and 11 patients with conventional brackets were selected for this study. The patients for this study were all treated by a qualified Post Graduate student.

Patient records were included with the following inclusion criteria:

1. First Premolar extraction cases.

2. Patients in the age group of 14-25.

3. Intra-oral photos and study models available at pretreatment (T0). at 10 weeks (T1) and 20 weeks (T2) postbonding.

4. Self ligating group treated with Damon Q brackets and Conventional brackets with MBT (3M Unitek).

5. The patients were reviewed every 5 weeks once.

6 . The same wire sequence was followed in both the groups.

20 patients (12 females, 8 males) fulfilled the inclusion criteria. The pre-treatment characteristics were recorded including the $\mathrm{Pa}-$ tients' age, sex, mandibular and maxillary crowding, irregularity index, extraction space and inter-canine width.
All study models were evaluated by using Little's irregularity in$\operatorname{dex}[15,18,19]$ to quantify the alignment of the 6 anterior teeth. Crowding was calculated as the difference between the sum of tooth widths and arch circumference taken from the line of best fit, through the contact points mesial to the first molars, on a photocopy of the patient's occlusal archform. Extraction space was measured from the closest points on the adjacent teeth before extraction. Intercanine width was measured from the cusp tip of the canines. The study models were measured with electronic calipers with sharpened tips that were accurate to $0.01 \mathrm{~mm}$. All model measurements were made by the primary researcher (E.O.).

The difference in irregularity scores was used to determine the sample size. Based on a previous study, at a power of $80 \%$ and a level of significance of 0.05 , would require a minimum of 10 patients per treatment group. In the final sample of 20 patients, 18 arches were treated with SL brackets and 22 arches with CL brackets.

Two-sample $t$ tests were performed at T0, T1, and T2 to compare the bracket groups for irregularity scores, residual extraction space and intercanine widths. Also, logistic regression was used to determine if there was a difference between the SL and CL bracket groups.

\section{Results and Discussion}

Two-sample t-test for assessing the difference between pre- and post- treatment values among the groups were performed. A chisquare test was done to find the association between the gender and the type of ligation.

Among 20 samples, 60\% were females and 40\% were males [Figure 1]. And among these, $55 \%$ used conventional ligation brackets and $45 \%$ used self-ligating brackets [Figure 2].

Chi-square test was performed to associate between gender and type of brackets used and was found to be not significant $(\mathrm{p}>0.05)$ [Figure 3]. Conventional brackets were more commonly preferred by females; the association was not statistically significant.

Twenty patients (12 females and 8 males) fulfilled the inclusion criteria. A total of 40 arches, 18 treated with SL brackets and 22 treated with CL brackets.

The mean irregularity index decreased in both groups over time (Table 1). During the first 10 weeks of treatment, both groups

Figure 1. Pie chart depicting the gender distribution of study population. $60 \%$ were females and $40 \%$ were males.

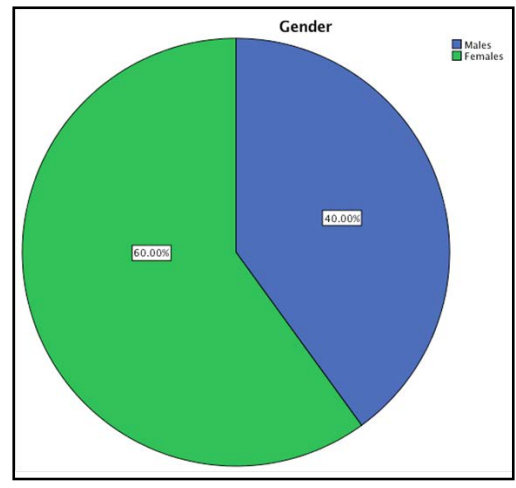


Figure 2. Pie Chart depicting frequency distribution of the type of bracket among the subjects. 55\% of study population conventional ligating brackets were used and $45 \%$ self ligating brackets.

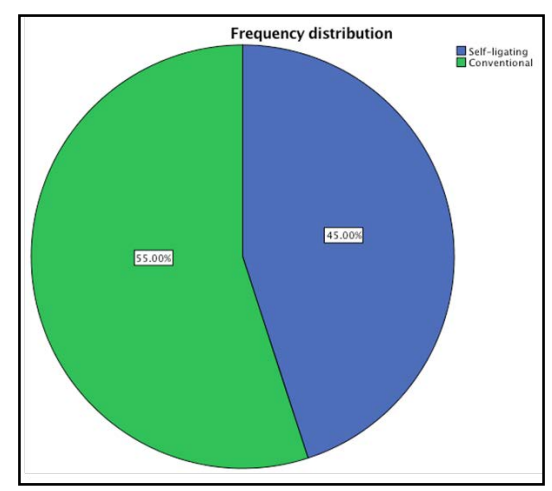

Figure 3. Bar graph showing the association between gender and the type of brackets used. The $\mathrm{X}$ axis shows the gender distribution and the $\mathrm{Y}$ axis shows the percentage of subjects using SL and CL brackets. Association between gender and type of brackets was done using chi square test and was found to be not significant. Chi square value $-p$ value $=0.7$ ( $p>0.05$ statistically not significant).Conventional ligation brackets were more commonly preferred by females but the association was not statistically significant.

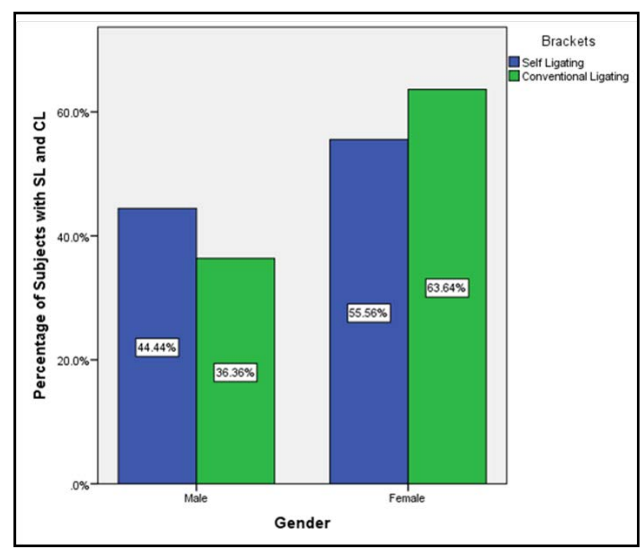

Table 1. Descriptive statistics for the irregularity index and mean extraction space (2-sample $t$ test). It was inferred that the mean irregularity index decreased in both groups over time. During the first 10 weeks of treatment, both groups had greater decrease in irregularity as compared to subsequent 10 weeks, but between the groups it was not statistically significant $(\mathrm{p}>0.05)$.

\begin{tabular}{|c|c|c|c|c|c|c|}
\hline & \multicolumn{3}{|c|}{ MANDIBULAR ARCH } & \multicolumn{3}{c|}{ MAXILLARY ARCH } \\
\hline & SL mean (SD) & CL mean (SD) & P Value & SL mean (SD) & CL mean (SD) & P Value \\
\hline Irregularity index, T0 & $10.75(4.72)$ & $11.45(5.26)$ & 0.39 & $11.64(5.55)$ & $11.96(7.2)$ & 0.73 \\
\hline Mean extraction space, T0 & $7.26(0.75)$ & $7.38(0.96)$ & 0.78 & $7.59(1.92)$ & $7.97(1.17)$ & 0.65 \\
\hline Irregularity index, T1 & $3.79(3.63)$ & $3.94(2.87)$ & 0.74 & $5.36(3.72)$ & $5.52(4.46)$ & 0.79 \\
\hline Mean extraction space, T1 & $5.08(1.43)$ & $4.89(1.56)$ & 0.31 & $5.41(1.74)$ & $5.12(1.73)$ & 0.34 \\
\hline Irregularity index, T2 & $2.37(1.86)$ & $2.26(1.72)$ & 0.57 & $4.14(2.69)$ & $4.04(2.59)$ & 0.76 \\
\hline Mean extraction space, T2 & $3.86(1.78$ & $3.93(1.65)$ & 0.95 & $4.20(2.13)$ & $3.94(1.76)$ & 0.47 \\
\hline
\end{tabular}

had greater decrease in irregularity as compared to subsequent 10 weeks. Also, there was no statistically significant difference between the treatment groups at $\mathrm{T} 1$ or $\mathrm{T} 2$.

For extraction space closure, the residual extraction spaces were measured. The mean values are given in table 1 . There is no significant difference.

The mean changes in arch dimension from T0 to T2 were calculated for each arch (Table 2). There was no statistical significant difference between the groups $(\mathrm{p}>0.05)$. The changes were greater in mandibular and maxillary intercanine widths. Mandibular intercanine width was observed to increase from T0 to T2:
1.83 and $2.69 \mathrm{~mm}$ in the SL and CL groups, respectively. Maxillary intercanine width was observed to increase from T0 to T2: 2.64 and $3.19 \mathrm{~mm}$ in the SL and CL groups, respectively.

Studies have demonstrated that SL brackets generate significantly lower levels of in-vitro friction than do CL brackets [4, 15, 18, 19]. This has led to increased promotion of SL brackets on the speculation that decreased friction leads to improved clinical efficiency. However, this study agrees with the growing body of evidence that there is no statistically significant difference in treatment efficiency between SL and CL brackets during initial alignment. Our study demonstrated that Damon 3MX SL brackets were no more efficient than Victory Series and Mini-Diamond CL brackets in 
Table 2. Mean changes in intercanine width (T0-T2) in millimeters (2-sample t test). The mean changes in arch dimension from $\mathrm{T} 0$ to $\mathrm{T} 2$ were calculated for each arch. It was observed that there was no statistical significant difference between the two groups in the maxillary and mandibular arches.

\begin{tabular}{|c|c|c|c|c|c|c|}
\hline & \multicolumn{3}{|c|}{ MANDIBULAR ARCH } & \multicolumn{3}{c|}{ MAXILLARY ARCH } \\
\hline & SL mean (SD) & CL mean (SD) & P Value & SL mean (SD) & CL mean (SD) & P Value \\
\hline Intercanine width & $1.83(1.68)$ & $2.69(2.58)$ & 0.31 & $2.64(2.38)$ & $3.19(4.05)$ & 0.63 \\
\hline
\end{tabular}

anterior alignment or passive extraction space closure during the first 20 weeks of orthodontic treatment.

Previous clinical studies by Eberting et al., [2] and Harradine [13], reported decreased total treatment time and fewer appointments for patients treated with Damon SL brackets. However, these retrospective studies were both potentially subject to bias. The effect of confounding factors might have been considerable because the selection criteria were not well detailed, the pretreatment characteristics of the sample were not tested for equivalence, (2) and clinical variables such as archwire sequences were different in each bracket group.

Subsequent well-designed retrospective and prospective clinical studies reported no significant differences in treatment efficiency between SL and CL brackets during initial alignment [14-17] and active space closure $[16,17]$. Majority of these studies evaluated the alignment efficiency of the mandibular anterior arch as rotations, irregularity, and small interbracket distances are typically encountered in this region.

We used the same initial archwire sequence as that of Scott et al, which included 0.014 -in and 0.014 x 0.025-in copper-nickeltitanium archwires in the Damon archform. The SL group of Pandis et al [15] also used the same sequence. Similar changes in arch dimensions were observed in all patients with these archwires regardless of the bracket type used. Therefore, the dimensional changes can be attributed to the Damon archform. Mean mandibular intercanine width increased, mandibular intermolar widths decreased, and arch depths decreased. Mandibular intercanine width increased by averages of 1.83 and $2.69 \mathrm{~mm}$ in the SL and CL groups, respectively. Scott et al reported similar increases of 2.38 and $2.47 \mathrm{~mm}$ in SL and CL groups, respectively.

Mean maxillary intercanine width increased by 2.83 and $3.4 \mathrm{~mm}$ in the SL and CL groups, respectively. The increase in maxillary intermolar width in both bracket groups were insignificant. Interestingly, maxillary and mandibular intercanine width increased despite the extractions. This might be due to the distal movement of the canines into the extraction spaces. These findings discredit previous suggestions that premolar extractions inevitably cause "shrinking" of the dental arch, increased buccal corridors, and damage to smile esthetics $[15,20]$. Furthermore, studies have shown that buccal corridors do not influence smile esthetics [15, 20, 21].

The results from this study concur with previous studies that found no difference in the alignment of mandibular teeth in extraction patients with severe irregularity. The mean irregularity scores in the study of Scott et al were $12.44 \mathrm{~mm}$ in the CL group and $11.23 \mathrm{~mm}$ in the SL group. Similarly, the patients we investigated had severe irregularity scores. Pandis et al investigated mod- erate and severe irregularity. They reported no significant difference in subjects with severe irregularity scores greater than five. Interestingly, they found that patients with moderate irregularity, with irregularity scores between 2 and 5 , were 2.7 times more likely to align faster in the SL bracket treatment group. Different archwire sequences were used in each bracket group in the study of Pandis et al [18]; this might have been a confounding factor contributing to the hazard ratio [22-36].

\section{Conclusion}

Within the limitations of the study it can be concluded that both self ligation and conventional ligation were equally effective in alignment of lower anterior teeth. Rate of decrowding was more with conventional brackets but not significant statistically and conventional brackets are more popular among females.

\section{Acknowledgement}

I would like to record my deep sense of gratitude to my research supervisor Dr. Naveen Kumar M, Senior lecturer, Department of Orthodontics, Saveetha Dental College and Hospitals, Chennai for his inspiring guidance and encouragement with my work during all stages. There was an equal contribution from all the authors.

\section{References}

[1]. Turnbull NR, Birnie DJ. Treatment efficiency of conventional vs self-ligating brackets: effects of archwire size and material. Am J Orthod Dentofacial Orthop. 2007 Mar;131(3):395-9.Pubmed PMID: 17346597.

[2]. Eberting JJ, Straja SR, Tuncay OC. Treatment time, outcome, and patient satisfaction comparisons of Damon and conventional brackets. Clin Orthod Res. 2001 Nov;4(4):228-34.Pubmed PMID: 11683812.

[3]. Ehsani S, Mandich MA, El-Bialy TH, Flores-Mir C. Frictional resistance in self-ligating orthodontic brackets and conventionally ligated brackets. A systematic review. Angle Orthod. 2009 May;79(3):592-601.Pubmed PMID: 19413397.

[4]. Pizzoni L, Ravnholt G, Melsen B. Frictional forces related to self-ligating brackets. The Eur. J. Orthod. 1998 Jun 1;20(3):283-91.

[5]. Kapur R, Sinha PK, Nanda RS. Comparison of frictional resistance in titanium and stainless steel brackets. Am J Orthod Dentofacial Orthop. 1999 Sep 1;116(3):271-4.

[6]. Hain M, Dhopatkar A, Rock P. The effect of ligation method on friction in sliding mechanics. Am J Orthod Dentofacial Orthop. 2003 Apr;123(4):41622.Pubmed PMID: 12695769.

[7]. Shivapuja PK, Berger J. A comparative study of conventional ligation and self-ligation bracket systems. Am J Orthod Dentofacial Orthop. 1994 Nov;106(5):472-80.Pubmed PMID: 7977187.

[8]. Henao SP, Kusy RP. Evaluation of the frictional resistance of conventional and self-ligating bracket designs using standardized archwires and dental typodonts. Angle Orthod. 2004 Apr;74(2):202-11.Pubmed PMID: 15132446.

[9]. Kapila S, Angolkar PV, Duncanson MG Jr, Nanda RS. Evaluation of friction between edgewise stainless steel brackets and orthodontic wires of four alloys. Am J Orthod Dentofacial Orthop. 1990 Aug;98(2):117-26.Pubmed PMID: 2378317.

[10]. Andreasen GF, Quevedo FR. Evaluation of friction forces in the $0.022 \times$ 
0.028 edgewise bracket in vitro. J Biomech. 1970 Mar;3(2):151-60.Pubmed PMID: 5521536.

[11]. Frank CA, Nikolai RJ. A comparative study of frictional resistances between orthodontic bracket and arch wire. Am J Orthod. 1980 Dec;78(6):593-609. Pubmed PMID: 6935961.

[12]. Braun S, Bluestein M, Moore BK, Benson G. Friction in perspective. Am J Orthod Dentofacial Orthop. 1999 Jun 1;115(6):619-27.

[13]. Harradine NW. Self-ligating brackets and treatment efficiency. Clin Orthod Res. 2001 Nov;4(4):220-7.

[14]. Miles PG, Weyant RJ, Rustveld L. A clinical trial of Damon 2 vs conventional twin brackets during initial alignment. Angle Orthod. 2006 May;76(3):4805.Pubmed PMID: 16637731.

[15]. Pandis N, Polychronopoulou A, Eliades T. Self-ligating vs conventional brackets in the treatment of mandibular crowding: a prospective clinical trial of treatment duration and dental effects. Am J Orthod Dentofacial Orthop. 2007 Aug;132(2):208-15.Pubmed PMID: 17693371.

[16]. Hamilton R, Goonewardene MS, Murray K. Comparison of active self-ligating brackets and conventional pre-adjusted brackets. Aust Orthod J. 2008 Nov;24(2):102-9.Pubmed PMID: 19113074.

[17]. Miles PG. Self-ligating vs conventional twin brackets during en-masse space closure with sliding mechanics. Am J Orthod Dentofacial Orthop. 2007 Aug;132(2):223-5.Pubmed PMID: 17693373.

[18]. Scott P, DiBiase AT, Sherriff M, Cobourne MT. Alignment efficiency of Damon3 self-ligating and conventional orthodontic bracket systems: a randomized clinical trial. Am J Orthod Dentofacial Orthop. 2008 Oct;134(4):470.e1-8.Pubmed PMID: 18929262.

[19]. Little RM. The irregularity index: a quantitative score of mandibular anterior alignment. Am J Orthod. 1975 Nov;68(5):554-63.Pubmed PMID: 1059332.

[20]. Witzig JW, Spahl TJ. The clinical management of basic maxillofacial orthopedic appliances. Hong Kong: Year Book Medical. 1987;1:146.

[21]. Hulsey CM. An esthetic evaluation of lip-teeth relationships present in the smile. Am. J. Orthod. 1970 Feb 1;57(2):132-44.

[22]. Sivamurthy G, Sundari S. Stress distribution patterns at mini-implant site during retraction and intrusion--a three-dimensional finite element study. Prog Orthod. 2016;17:4.Pubmed PMID: 26780464.

[23]. Samantha C, Sundari S, Chandrasekhar S, Sivamurty G, Dinesh S. Comparative Evaluation of Two Bis-GMA Based Orthodontic Bonding Adhesives - A Randomized Clinical Trial. J Clin Diagn Res. 2017 Apr;11(4):ZC40ZC44.Pubmed PMID: 28571259.

[24]. Krishnan S, Pandian S, Kumar S A. Effect of bisphosphonates on orthodon- tic tooth movement-an update. J Clin Diagn Res. 2015 Apr;9(4):ZE01-5. Pubmed PMID: 26023659.

[25]. Vikram NR, Prabhakar R, Kumar SA, Karthikeyan MK, Saravanan R. Ball Headed Mini Implant. J Clin Diagn Res. 2017 Jan;11(1):ZL02-3.

[26]. Kamisetty SK, Verma JK, Arun, Sundari S, Chandrasekhar S, Kumar A. SBS vs Inhouse Recycling Methods-An Invitro Evaluation. J Clin Diagn Res. 2015 Sep;9(9):ZC04-8.Pubmed PMID: 26501002.

[27]. Viswanath A, Ramamurthy J, Dinesh SP, Srinivas A. Obstructive sleep apnea: awakening the hidden truth. Niger J Clin Pract. 2015 Jan-Feb;18(1):1-7. Pubmed PMID: 25511335.

[28]. Felicita AS. Quantification of intrusive/retraction force and moment generated during en-masse retraction of maxillary anterior teeth using mini-implants: A conceptual approach. Dental Press J Orthod. 2017 SepOct;22(5):47-55.Pubmed PMID: 29160344.

[29]. Rubika J, Felicita AS, Sivambiga V. Gonial angle as an indicator for the prediction of growth pattern. World J Dent. 2015;6(3):161-3.

[30]. Jain RK, Kumar SP, Manjula WS. Comparison of intrusion effects on maxillary incisors among mini implant anchorage, j-hook headgear and utility arch. J Clin Diagn Res. 2014 Jul;8(7):ZC21-4.Pubmed PMID: 25177631.

[31]. Pandian KS, Krishnan S, Kumar SA. Angular photogrammetric analysis of the soft-tissue facial profile of Indian adults. Indian J Dent Res. $2018 \mathrm{Mar}$ Apr;29(2):137-143.Pubmed PMID: 29652003.

[32]. Ramesh Kumar KR, Shanta Sundari KK, Venkatesan A, Chandrasekar S. Depth of resin penetration into enamel with 3 types of enamel conditioning methods: a confocal microscopic study. Am J Orthod Dentofacial Orthop. 2011 Oct;140(4):479-85.Pubmed PMID: 21967934.

[33]. Felicita AS. Orthodontic management of a dilacerated central incisor and partially impacted canine with unilateral extraction - A case report. Saudi Dent J. 2017 Oct;29(4):185-193.Pubmed PMID: 29033530.

[34]. Felicita AS, Chandrasekar S, Shanthasundari KK. Determination of craniofacial relation among the subethnic Indian population: a modified approach - (Sagittal relation). Indian J Dent Res. 2012 May-Jun;23(3):305-12. Pubmed PMID: 23059564.

[35]. Dinesh SP, Arun AV, Sundari KK, Samantha C, Ambika K. An indigenously designed apparatus for measuring orthodontic force. J Clin Diagn Res. 2013 Nov;7(11):2623-6.Pubmed PMID: 24392423.

[36]. Felicita AS. Orthodontic extrusion of Ellis Class VIII fracture of maxillary lateral incisor - The sling shot method. Saudi Dent J. 2018 Jul;30(3):265269.Pubmed PMID: 29942113. 